\title{
Adsorption of Copper (II) Ions in Aqueous Solution by a Natural Mouka Smectite and an Activated Carbon Prepared from Kola Nut Shells by Chemical Activation with Zinc Chloride $\left(\mathrm{ZnCl}_{2}\right)$
}

\author{
Phil Lewis Mpampoungou Langama*, Jean Jacques Anguile, Albert Novy Messi Me Ndong, \\ Adam Bouraima, Crislain Bissielou
}

Laboratoire de Chimie des Matériaux Inorganiques, Faculté des Sciences, Département de Chimie, Université des Sciences et Techniques de Masuku, Franceville, Gabon

Email: *jjanguile@yahoo.com

How to cite this paper: Langama, P.L.M., Anguile, J.J., Ndong, A.N.M.M., Bouraima, A. and Bissielou, C. (2021) Adsorption of Copper (II) Ions in Aqueous Solution by a Natural Mouka Smectite and an Activated Carbon Prepared from Kola Nut Shells by Chemical Activation with Zinc Chloride $\left(\mathrm{ZnCl}_{2}\right)$. Open Journal of Inorganic Chemistry, 11, 131-144.

https://doi.org/10.4236/ojic.2021.114009

Received: February 18, 2021

Accepted: October 23, 2021

Published: October 26, 2021

Copyright $\odot 2021$ by author(s) and Scientific Research Publishing Inc. This work is licensed under the Creative Commons Attribution International License (CC BY 4.0).

http://creativecommons.org/licenses/by/4.0/

\begin{abstract}
The aim of this work was to test the adsorption efficiency of copper (II) ions in an aqueous solution on Natural Smectite (NS) and Activated Carbon (AC). The experiments carried out in batch mode made it possible to determine the stirring time, the adsorbent mass, the $\mathrm{pH}$, the initial concentration of copper (II) ions, the isotherms and the adsorption kinetics. It appears that the stirring time was 15 minutes for the $\mathrm{AC}$ and 20 minutes for the NS. The adsorption was at maximum for the two adsorbents at optimum $\mathrm{pH}$ of 3.5 for a mass of $0.05 \mathrm{~g}$ each. The quantity of copper (II) ions adsorbed was $26.6 \mathrm{mg} / \mathrm{L}$ for NS and $36.6 \mathrm{mg} / \mathrm{g}$ for AC of a concentration of $600 \mathrm{mg} / \mathrm{L}$ each. The Langmuir isotherm was the one that best described the adsorption process for the two adsorbents. The adsorption kinetics obtained was that of the pseudo secondorder for our two adsorbents. The results obtained showed that these two adsorbents were effective for the adsorption of copper (II) ions in an aqueous solution.
\end{abstract}

\section{Keywords}

Batch, Isotherm, Kinetics, Adsorption, Activated Carbon, Natural Smectite

\section{Introduction}

Industrial activities have contributed to the development of several countries, 
but have also generated several types of pollution. The water sector is the most affected after the discharge of industrial effluents into lakes and rivers causing pollution by heavy metals, dyes, etc.

Heavy metals are highly toxic species above a certain concentration. They have the ability to concentrate along the food chain and accumulate in certain organs of the human body [1]. Among these heavy metals, we cite copper, which is an essential element for all living organisms including humans. The presence of copper in water at high concentrations causes significant health problems such as greenish vomiting, abdominal pain, diarrhea, kidney and liver damage [2]. According to the World Health Organization (WHO) guidelines for drinking water quality, the limit for copper in drinking water is $2 \mathrm{mg} / \mathrm{L} \mathrm{[3]} \mathrm{[4].} \mathrm{Copper} \mathrm{is} \mathrm{used}$ extensively in the electrical, metallurgical, mining and agricultural industries. Reducing the level of copper in natural waters is therefore a major concern, in order to comply with the drinkable standard and to avoid any health risk linked to its toxicity. In addition, the reduction in the level of copper in natural waters is significant in Gabon because of the strong activity of the exploitation of heavy metals such as copper, by the Ogooué Mining Company (Comilog) after the discharge into groundwater; but also because of the growing agricultural sector (the population nowadays takes an interest in this sector of activity) with companies like Olam Gabon and the Seed Project.

To this end, several methods such as chemical precipitation, ion exchange, membrane processes, adsorption, reverse osmosis or electrochemical treatment, have been applied to remove excess copper in water [5]. Of all these methods, it appears that adsorption is the most valued method in the field of water treatment because it is simple, less expensive and easily reproducible. It uses materials of natural origin, organic, available, low cost, easy to use and to regenerate [6]. Currently, activated carbons are widely used as adsorbents for discoloration [7], to scavenge heavy metals [8] [9], pharmaceuticals [10] and pesticides [11]. Indeed, activated carbon is one of the most effective ways to remove a wide range of contaminants. In recent years, clays are new adsorbents [12] [13]. Their abundance and their ability to retain pollutants make them the objectives of several studies.

Thus the objective of this work is to test the adsorption capacity of copper (II) ions on a natural smectite and an activated carbon. To achieve this, various parameters were studied, namely, the influence of the stirring time, the mass of the adsorbents, the $\mathrm{pH}$, the initial concentration, the adsorption isotherms and the adsorption kinetics.

\section{Material and Methods}

\subsection{Material}

\section{Adsorbents}

Activated carbons: The raw material consisting of cola nut shells was harvested in the North West region of Cameroon, more precisely in the department of Donga-Mantun. The harvested pods are washed thoroughly under running water to 
remove impurities, rinsed with distilled water, and then dried in the sun for two weeks. Once dried, these pods are crushed to a debris size between 1.25 and 2.5 $\mathrm{mm}$. The biomass thus ground is impregnated with $\mathrm{ZnCl}_{2}$ with a ratio equal to 1 and then dried at a temperature of $110^{\circ} \mathrm{C}$ for $24 \mathrm{~h}$. The carbonization of our material took place at $500^{\circ} \mathrm{C}$ for 1 hour and the cooling took place gradually to room temperature. The charcoal obtained from the char was washed with distilled water to the negative test for $\mathrm{AgNO}_{3}$ and was dried at $110^{\circ} \mathrm{C}$ for 24 hours before being powdered. The characterization of this coal has already been the subject of a publication [14] and Table 1 below presents some characteristics of this coal.

Natural smectite: The rough clay soil aggregates were collected in the locality of Soukamna located $6 \mathrm{~km}$ from the Mayo Danay department (Yagoua capital) in the far north region of Cameroon. Once extracted, these aggregates were washed abundantly with distilled water to be freed of impurities and put to rest for a determined time: there is sedimentation. The clay suspension was siphoned off and the residue was oven dried at $110^{\circ} \mathrm{C}$ until the water had completely evaporated. Then, the clay was crushed in a porcelain mortar, and then fractionated with a $50 \mu \mathrm{m}$ mesh diameter sieve. The powder obtained was dried in an oven at a temperature of $200^{\circ} \mathrm{C}$ for 24 hours to remove the bound water. Finally, the material was placed in a beaker and was stored in a desiccator containing calcium chloride. The characterization of this natural smectite was the subject of a publication [15] in the previous study by our research team. Table 2 below gives the chemical composition of this natural smectite.

\subsection{Methods}

\subsubsection{Preparation of Solutions (Mother and Daughters)}

The $3000 \mathrm{mg} / \mathrm{L}$ copper (II) stock solution was prepared in the laboratory by dissolving $12.02 \mathrm{~g}$ of hydrated penta copper sulfate salt in a $1000 \mathrm{~mL}$ volumetric flask with distilled water. The daughter solutions of concentrations of 150, 300, $600,900,1200$ and $1800 \mathrm{mg} / \mathrm{L}$ used.

Table 1. Some characteristics of activated carbon [14].

\begin{tabular}{cc}
\hline Chemical activation & Values \\
\hline Specific surface $\left(\mathrm{m}^{2} / \mathrm{g}\right)$ & 647.7374 \\
Pore volume $\left(\mathrm{cm}^{3} / \mathrm{g}\right)$ & 0.332061 \\
Average pore diameter $(\mathrm{nm})$ & 3.8013 \\
Iodine mumber $(\mathrm{mg} / \mathrm{g})$ & 656.7075 \\
\hline
\end{tabular}

Table 2. Chemical composition of natural smectite.

\begin{tabular}{cccccccccccccccc}
\hline Oxides & $\mathrm{SiO}_{2}$ & $\mathrm{Al}_{2} \mathrm{O}_{3}$ & $\mathrm{Fe}_{2} \mathrm{O}_{3}$ & $\mathrm{CaO}$ & $\mathrm{MgO}$ & $\mathrm{K}_{2} \mathrm{O}$ & $\mathrm{Na}_{2} \mathrm{O}$ & $\mathrm{SO}_{3}$ & $\mathrm{TiO}_{2}$ & $\mathrm{Mn}_{2} \mathrm{O}_{3}$ & $\mathrm{P}_{2} \mathrm{O}_{5}$ & $\mathrm{PF}$ & Total \\
\hline$(\%)$ & 43.76 & 24.48 & 8.71 & 1.26 & 0.58 & 0.91 & 0.21 & 0.08 & 1.54 & 0.02 & 0.10 & 18.30 & 99.95 \\
\hline
\end{tabular}




\subsubsection{Batch Adsorption Experiment}

The experiments were carried out by contacting quantities of adsorbents $(0.05 \mathrm{~g}$; $0.1 \mathrm{~g} ; 0.2 \mathrm{~g} ; 0.3 \mathrm{~g}$ and $0.4 \mathrm{~g}$ ) with $20 \mathrm{~mL}$ of the solution of copper ions (II) at different initial concentrations ( $150 \mathrm{mg} / \mathrm{L}, 300 \mathrm{mg} / \mathrm{L}, 600 \mathrm{mg} / \mathrm{L}, 900 \mathrm{mg} / \mathrm{L}, 1200$ $\mathrm{mg} / \mathrm{L}$ and $1800 \mathrm{mg} / \mathrm{L}$ ). The mixtures are left under stirring for a time varying from 5 to 40 minutes as well as at a $\mathrm{pH}$ varying from 2 to 4.5 . After stirring, the mixtures are filtered and assayed using a UV/Visible spectrophotometer.

The amount adsorbed at equilibrium $\left(q_{e}\right)$ was calculated using Equation (1):

$$
q_{e}=\frac{c_{i}-c_{e}}{m} v
$$

where, $q_{e}$ is the amount of adsorbed at equilibrium $(\mathrm{mg} / \mathrm{g}), c_{i}$ is the initial concentration of adsorbate $(\mathrm{mg} / \mathrm{L}), c$ is the concentration of adsorbate at equilibrium $(\mathrm{mg} / \mathrm{L}), v$ is the volume of the solution $(\mathrm{L})$ and $m$ the mass of the adsorbent $(\mathrm{g})$.

We point out that this method was preferred over others during our study because it is simple and easily reproducible.

\subsubsection{Adsorption Isotherms Experiment}

The adsorption isotherm is a curve binding at a fixed temperature, the amount of impurities adsorbed per unit mass of adsorbent and the concentration of impurities in solution after absorption equilibrium. There are different models that will allow us to define the isotherm that best reproduces adsorption.

Langmuir isotherm: Its linear form is given by Equation (2):

$$
\frac{c_{e}}{q_{e}}=\frac{c_{e}}{q_{m}}+\frac{1}{k q_{m}}
$$

where, $q_{e}$ is the amount adsorbed at equilibrium $(\mathrm{mg} / \mathrm{g}), q_{m}$ is the maximum amount adsorbed $(\mathrm{mg} / \mathrm{g}), k$ is Langmuir's constant $(\mathrm{L} / \mathrm{mg})$ and $c_{e}$ is the adsorbate concentration at balance $(\mathrm{mg} / \mathrm{L})$.

The linear form of the Freundlich isotherm is given by Equation (3):

$$
\ln q_{e}=\ln k_{f}+\frac{1}{n} \ln c_{e}
$$

where, $k_{f}$ is the Freundlich constant $\left(\mathrm{mg}^{1-1 / n} \cdot \mathrm{L}^{1 / n} \cdot \mathrm{g}^{-1}\right)$ and $n$ is the Freundlich coefficient.

Dubinin-Kaganer-Radushkevich isotherm (D-K-R): its linear form is given by Equation (4):

$$
\ln q_{e}=\ln q_{m}-\beta \varepsilon^{2}
$$

where, the polanyi potential is $\varepsilon=R T \ln \left(1+\frac{1}{C_{e}}\right), R$ is the ideal gas constant $\left(\mathrm{J} \cdot \mathrm{mol}^{-1} \cdot \mathrm{K}^{-1}\right), T$ is the absolute temperature $(\mathrm{K})$ and $\beta$ is the constant related to energy adsorption $\left(\mathrm{mol}^{2} / \mathrm{J}^{2}\right)$.

Tempkin Isotherm: Its linear form is given by Equation (5):

$$
q_{e}=\frac{R T}{b} \ln \left(C_{e}\right)+\frac{R T}{b} \ln (A)
$$


where $q_{e}$ is the amount adsorbed at equilibrium $(\mathrm{mg} / \mathrm{g})$, it is the concentration of adsorbate at equilibrium $(\mathrm{mg} / \mathrm{L}), R$ is the ideal gas constant, $T$ is the absolute temperature (K), $A$ is the Tempkin constant $(\mathrm{L} / \mathrm{mg})$ and $b$ is the adsorption exchange energy $(\mathrm{J} / \mathrm{mol})$.

\subsubsection{Adsorption Kinetics}

The adsorbate kinetics study describes the rate at which solutes are adsorbed and this rate controls the residence time of the adsorbate attached to the solid-solution interface.

Pseudo-first order model: Its linear form and given by Equation (6):

$$
\ln \left(q_{e}-q_{t}\right)=\ln q_{e}-k_{1} t
$$

where, $k_{1}$ is the adsorption rate constant $\left(\mathrm{min}^{-1}\right)$ and $q_{t}$ is the amount adsorbed at time $t(\mathrm{mg} / \mathrm{g})$.

The linear form of the pseudo-second order model is given by Equation (7):

$$
\frac{t}{q_{t}}=\frac{1}{k_{2} q_{e}^{2}}+\frac{t}{q_{e}}
$$

where, $k_{2}$ is the pseudo-second order rate constant $(\mathrm{g} / \mathrm{mg} / \mathrm{min})$.

Elovich's model: its linear form is given by Equation (8):

$$
q_{t}=\frac{1}{\beta} \ln (\alpha \beta)+\frac{1}{\beta} \ln (t)
$$

where, $\alpha$ is the initial adsorption rate $(\mathrm{mg} / \mathrm{g} / \mathrm{min})$ and $\beta$ is the adsorption constant (g/mg).

The intra-particle diffusion model is represented by Equation (9):

$$
q_{t}=k_{i d} t^{1 / 2}+c_{i}
$$

where, $k_{i d}$ is the intra-particulate diffusion rate constant $\left(\mathrm{mg} / \mathrm{g} / \mathrm{min}^{2}\right), c_{i}$ is the layer thickness and $t$ is the contact time ( $\mathrm{min})$.

\section{Results and Discussion}

\subsection{Influence of Stirring Time}

The adsorption of copper (II) ions from an aqueous solution of $600 \mathrm{mg} / \mathrm{L}$ concentration was carried out on $0.05 \mathrm{~g}$ of each adsorbent (NS and AC) at times varying between 5 and 40 minutes. Figure 1 shows the influence of the stirring time on the two adsorbents.

Three distinct phases were observed in Figure 1 for the two adsorbents. For $\mathrm{SN}$, we first have a fast phase of 0 to 5 minutes, then a slow to equilibrium phase of 5 to 20 minutes, and finally an equilibrium phase of 20 to 40 minutes. The maximum quantity of copper (II) ions adsorbed is $18.3 \mathrm{mg} / \mathrm{g}$. For AC, there is a fast phase of 0 to 5 minutes, then a slow phase to equilibrium of 5 to 15 minutes and finally an equilibrium phase of 15 to 40 minutes. The maximum quantity of copper (II) ions adsorbed is $11 \mathrm{mg} / \mathrm{g}$.

The first phase is due to the fact that the adsorption sites are free on the surface 


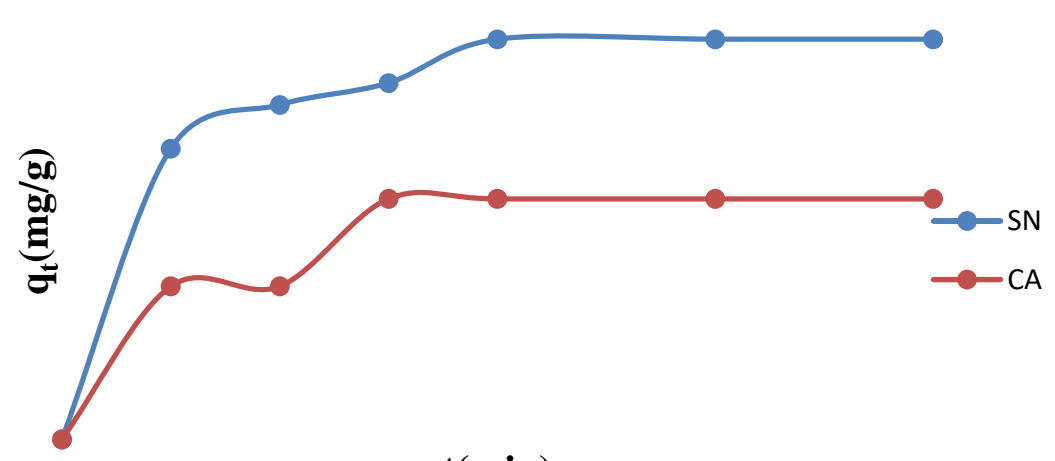

t(min)

Figure 1. Influence of the stirring time.

of the adsorbents. The second phase is due to the progressive saturation of these active sites. And the third phase is due to the complete saturation of these sites.

Indeed, the fixation of the first copper (II) ions in solution clogs the pores and prevents access to the ions remaining in solution.

These results corroborate with the work of Ouakouak and collaborator in 2016 [16] on the adsorption of $\mathrm{Cu}^{2+}$ ions on powdered activated carbon and sodium bentonic and those of Ajifack et al. in 2014 [17] on the adsorption of copper (II) ions on activated carbon. In the rest of our experiments, we will take 20 minutes for the NS and 15 minutes for the $\mathrm{AC}$ as equilibrium time.

\subsection{Influence of the Mass of the Adsorbents}

Figure 2 shows the evolution of the influence of the adsorbent mass.

The influence of the mass of the adsorbents was evaluated by varying the mass from 0.05 to $0.4 \mathrm{~g}$ in $20 \mathrm{~mL}$ of aqueous copper (II) ion solution at a concentration of $600 \mathrm{mg} / \mathrm{L}$. The stirring time is the optimum time determined previously (15 min for AC and $20 \mathrm{~min}$ for NS).

According to these curves, the adsorbed amounts decrease as the mass of the adsorbents increases. This could be explained by the fact that at high mass values, there is agglomeration of the adsorbent particles thus forming aggregates. These aggregates make it very difficult for copper (II) ions to access adsorption sites and lead to an increase in the path to be traveled by the pollutant. These results corroborate with the work of Zing et al. in 2016 [18] during the adsorption of ammonium ions on a natural smectite and an activated carbon activated with $\mathrm{ZnCl}_{2}$.

\subsection{Influence of $\mathrm{pH}$}

The effect of $\mathrm{pH}$ has been studied in the range of 2 to 4.5 . The optimum mass of the adsorbents determined previously was introduced into $20 \mathrm{~mL}$ of aqueous copper (II) ion solution with a concentration of $600 \mathrm{mg} / \mathrm{L}$. The stirring time is the optimal time. The results are shown in Figure 3.

Figure 3 shows that the amount of copper (II) ions adsorbed increases with increasing $\mathrm{pH}$ to 3.5 and then decreases. For NS, the quantity of copper (II) ions 


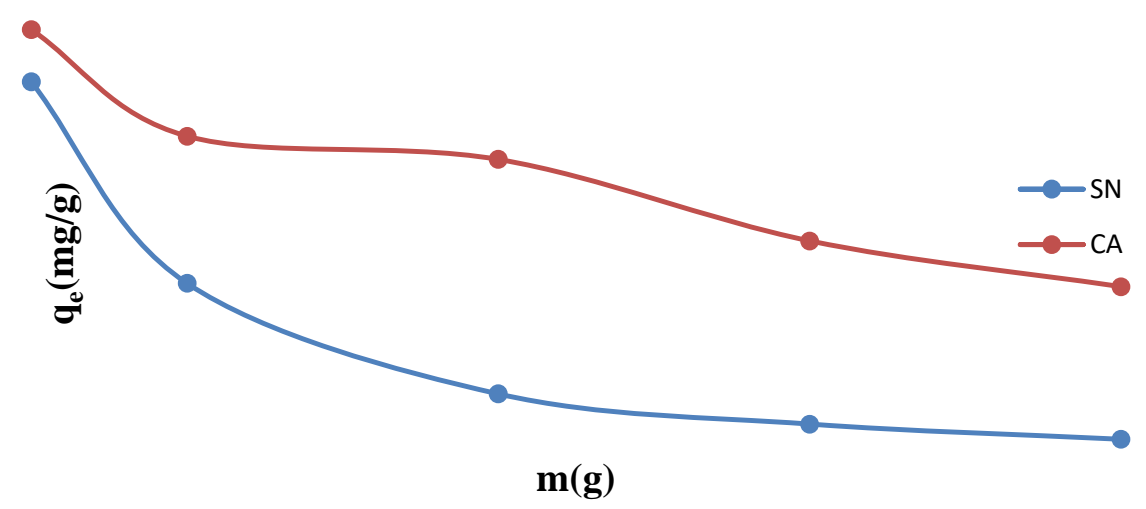

Figure 2. Influence of the mass of adsorbent.

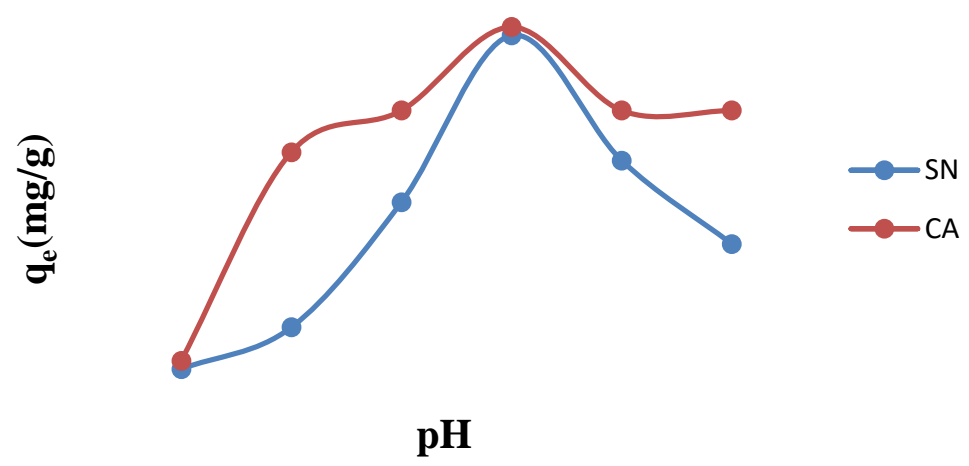

Figure 3. Curves showing the influence of $\mathrm{pH}$ on adsorbents.

adsorbed is very low at $\mathrm{pH}$ less than 2.5 . This could be explained by competition in the solution between copper (II) ions, $\mathrm{H}^{+}$ions and those of the compensating ions $\left(\mathrm{K}^{+}, \mathrm{Na}^{+}\right.$and $\left.\mathrm{Ca}^{2+}\right)$. On the other hand, at $\mathrm{pH}$ between 2.5 and 3.5, adsorption increases rapidly. This could be explained by the decrease in the number of $\mathrm{H}^{+}$ions in solution. The decrease in adsorption of copper (II) ions could be due to the reduction in the amount of negative charge on the clay surface. But also by the fact that when we approach the precipitation $\mathrm{pH}(\mathrm{pH}=5.01)$, there would be formation of copper hydroxide $\left(\mathrm{Cu}(\mathrm{OH})_{2}\right)$ which makes adsorption difficult. These results are similar to the work of Siéwé and collaborator in 2015 [19] on the activation of the surface sites of Andosol clay from Bambouto with phosphate ions.

For AC, the great adsorption of copper (II) ions in an acidic medium could be due to the fact that certain activated carbons behave in an acidic medium like Lewis bases. Some researchers attribute this phenomenon to the presence of oxygen complexes of heterocycles types (pyrone and chromene) which are rich in $\pi$ electrons and act as a Lewis base by accepting protons. In addition, we can also see that this basic character would be due to the chemisorption of dioxygen on the surface of the AC then forming peroxides $\left(\mathrm{O}_{2}^{2-}\right)$ which constitute basic electron donor-acceptor sites. These results are in agreement with those by Ghaedi and collaborator in 2015 [20] on the adsorption of copper (II) by an activated carbon. 


\subsection{Influence of the Initial Concentration of Copper (II) Ions}

The optimum mass ( $0.05 \mathrm{~g})$ of the adsorbents was and introduced into $20 \mathrm{~mL}$ of aqueous copper (II) ion solution of concentrations of 150, 300, 600, 900, 1200 and $1800 \mathrm{mg} / \mathrm{L}$. These solutions are adjusted beforehand to the optimum $\mathrm{pH}$ of each adsorbent. The stirring time is the optimal time. The results are shown in Figure 4.

We observe an increase in the adsorbed amounts depending on the initial cooper (II) ion concentrations. This increase in the amount adsorbed with the initial concentration of the metal is believed to be due to the fact that increasing the concentration of the metal increase the collision between the molecules of the metal and the sites of adsorption. These results are similar to the work of Essomba et al. in 2014 [21]. The two layers observed on our curves would be due to a first saturation then to a second saturation as in the work of Ivanova et al. in 2010 [22]. The amounts adsorbed by the AC are greater than those adsorbed by NS, which could be due to a higher number of active sites on the AC.

\subsection{Adsorption Isotherms}

Figures 5-8 below respectively represent the linear transforms of some models.

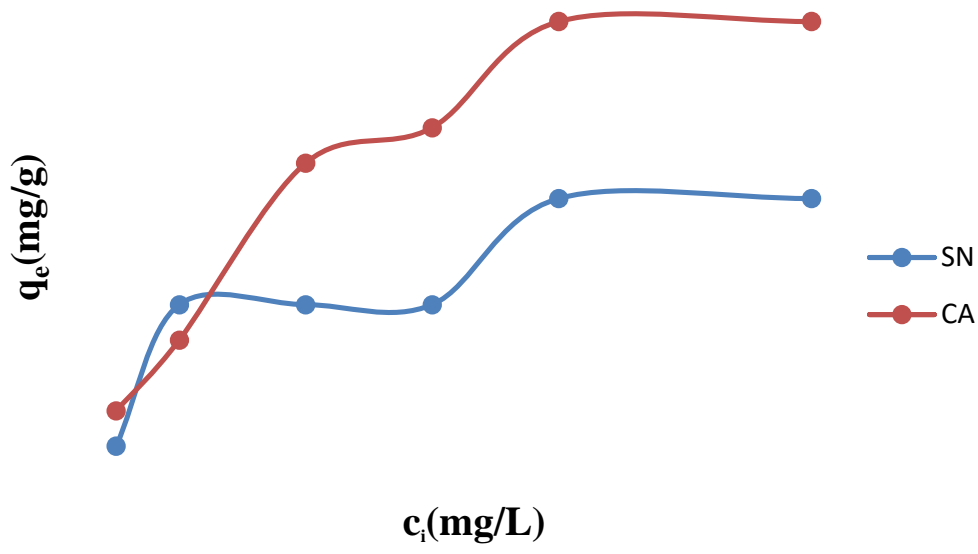

Figure 4. Influence of the initial concentration.

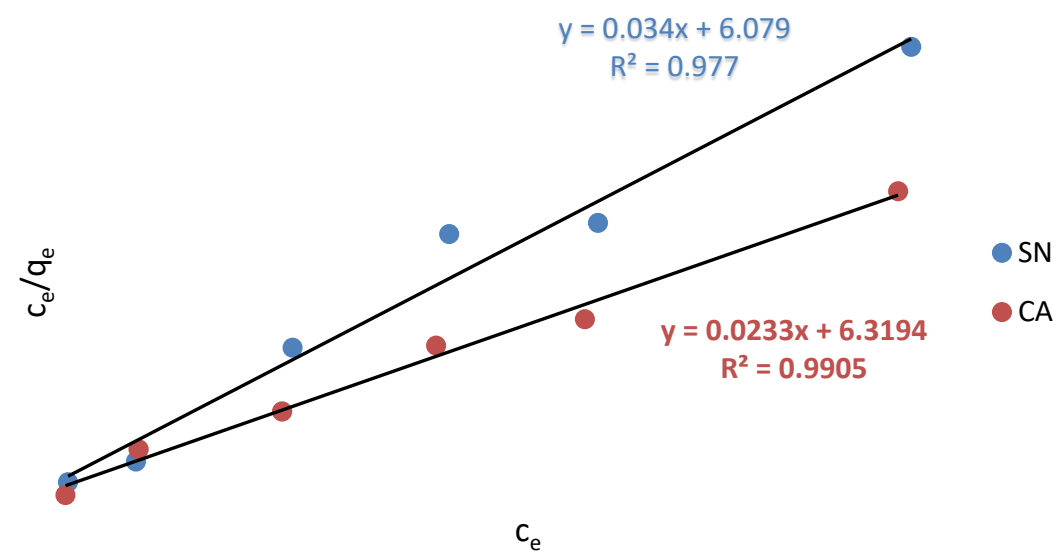

Figure 5. Linear transform of the Langmuir isotherm. 


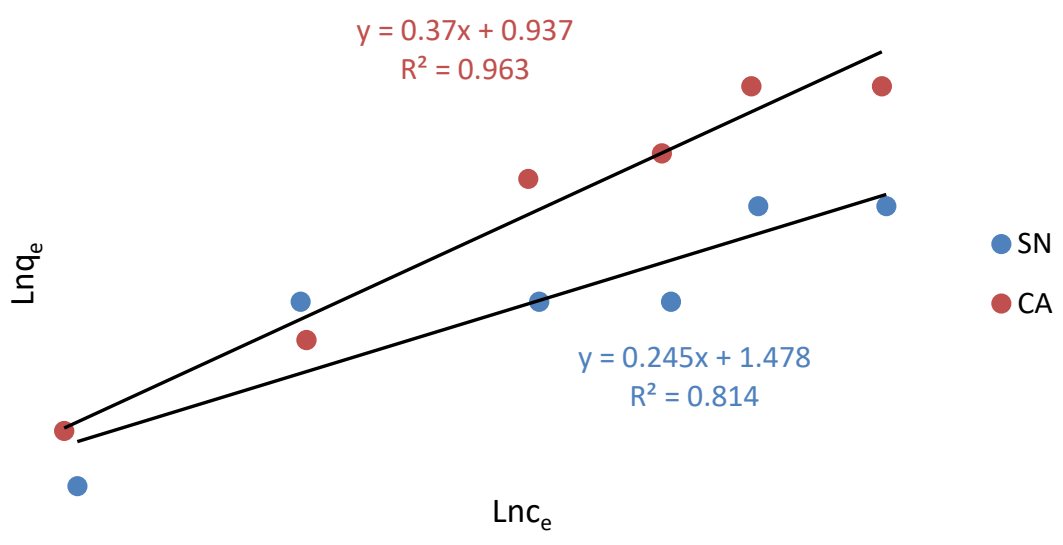

Figure 6. Linear transform of the Freundlich isotherm.

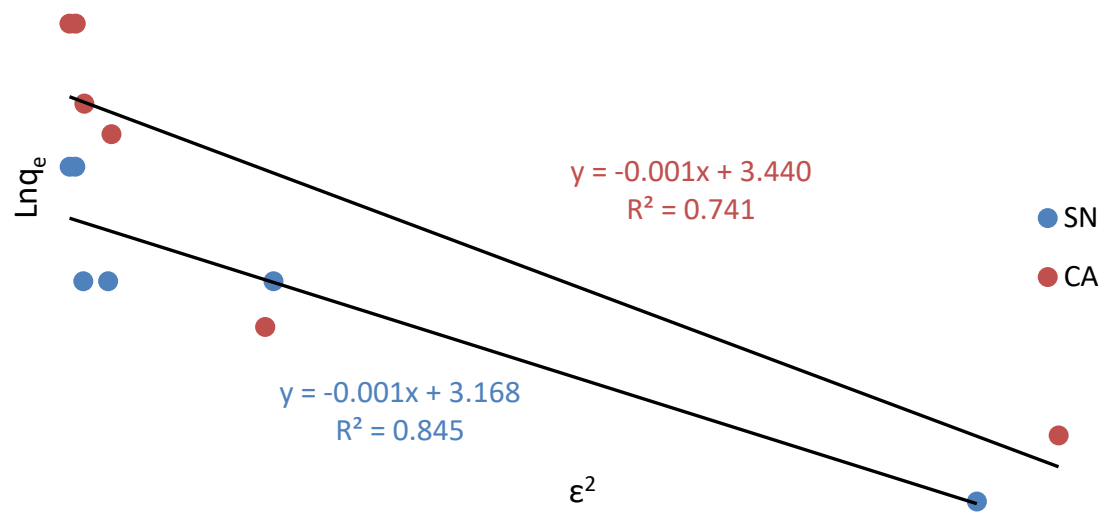

Figure 7. Linear transform of the isotherm of D-K-R.

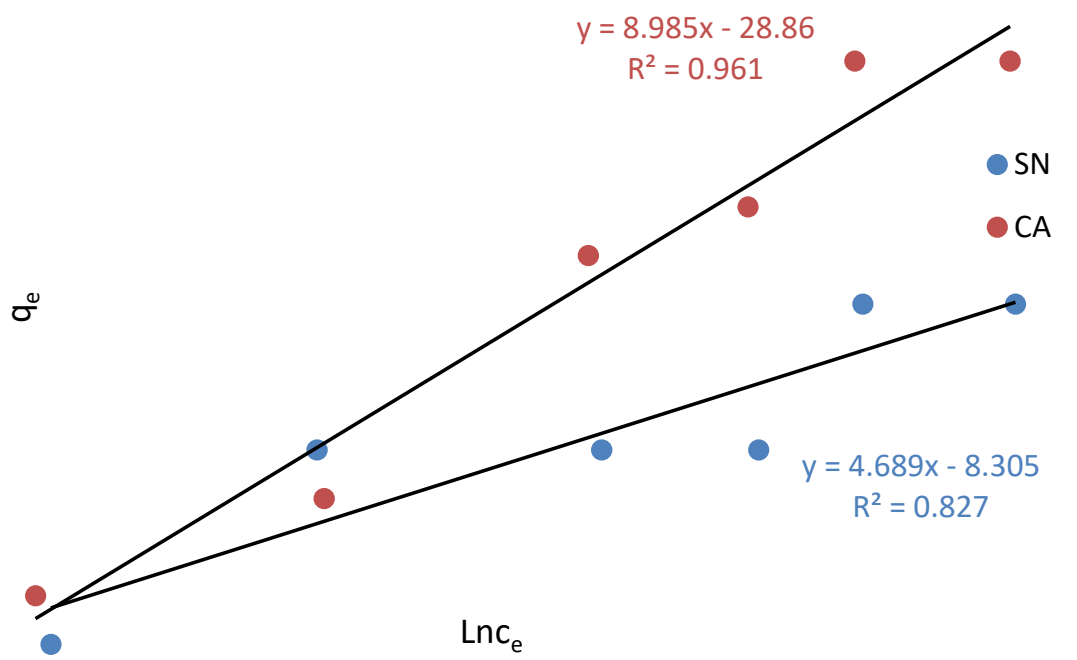

Figure 8. Linear transform of the Tempkin isotherm.

Table 3 presents the results of the constants and correlation coefficients of the linear transforms of some isothermal models.

In view of the data in this table, it appears that the highest correlation coefficient (close to unity) is that of Langmuir for the NS. This model describes well 
Table 3. The constants and models correlation isothermic.

\begin{tabular}{|c|c|c|c|}
\hline Isotherms & Parameters & NS & $\mathrm{AC}$ \\
\hline \multirow{5}{*}{ Langmuir } & $R^{2}$ & 0.9772 & 0.9905 \\
\hline & $q_{m}(\mathrm{mg} / \mathrm{g})$ & 28.82 & 42.92 \\
\hline & $q_{e}(\mathrm{mg} / \mathrm{g})$ & 26.6 & 36.6 \\
\hline & $K \cdot 10^{-4}(\mathrm{~L} / \mathrm{mg})$ & 57.07 & 36.87 \\
\hline & $R_{L}$ & 0.2260 & 0.3113 \\
\hline \multirow{3}{*}{ Freundlich } & $R^{2}$ & 0.8141 & 0.9633 \\
\hline & $K_{F}\left(\mathrm{mg}^{1-1 / n} \cdot \mathrm{L}^{1 / n} \cdot \mathrm{g}^{-1}\right)$ & 4.3872 & 2.5544 \\
\hline & $1 / \mathrm{n}$ & 0.2458 & 0.37 \\
\hline \multirow{5}{*}{$\mathrm{D}-\mathrm{K}-\mathrm{R}$} & $R^{2}$ & 0.8456 & 0.7412 \\
\hline & $q_{m}(\mathrm{mg} / \mathrm{g})$ & 23.77 & 31.20 \\
\hline & $q_{e}(\mathrm{mg} / \mathrm{g})$ & 26.6 & 36.6 \\
\hline & $\beta\left(\mathrm{mol}^{2} / \mathrm{J}^{2}\right)$ & 0.0015 & 0.0018 \\
\hline & $E(\mathrm{~kJ} / \mathrm{mol})$ & 0.0183 & 0.0167 \\
\hline \multirow{3}{*}{ Tempkin } & $R^{2}$ & 0.8275 & 0.9617 \\
\hline & $A(\mathrm{~L} / \mathrm{mg})$ & 0.1702 & 0.0403 \\
\hline & $b(\mathrm{~J} / \mathrm{mol})$ & 528.2782 & 275.7423 \\
\hline
\end{tabular}

the phenomenon of adsorption of copper (II) ions at the surface of NS because its Langmuir separation factor $\left(R_{L}\right)$ is between 0 and 1 .

For the AC, the correlation coefficients are those of the isotherm of Langmuir, Freundlich and Tempkin. Indeed, the value of $R_{L}$ is between 0 and 1 indicates that the Langmuir model is suitable. Then, the value of $1 / n$ being between 0 and 1 indicates that the surface of our AC is heterogeneous. Finally, Tempkin indicates that chemical adsorption is the major mechanism involved. All this partially indicates chemisorption but with the possibility of the formation of several layers on heterogeneous surfaces.

\subsection{Study of Kinetic Models}

The results of the adsorption mechanism of copper (II) ions on our adsorbents are represented by Figures 9-12.

Table 4 presents the results of the rate constants and correlation coefficients of the linear transforms of some kinetic models.

In view of the results of Table 4, we find that the adsorption of copper (II) ions by the adsorbents is best described by the pseudo-second order model with the highest correlation coefficients. This indicates that chemisorption is the limiting step in this process. These results are consistent with the work of Ketcha and collaborator in 2012 [23]. In addition, the theoretical and experimental adsorbed quantities are close, which further confirms this chemisorption.

The high value of the correlation coefficient of the Elovich model for the NS $\left(R^{2}=0.9145\right)$ shows that the adsorption takes place in multilayers, which agrees with the type of isotherm obtained with the influence of the concentration at the balance. These results are consistent with the work of Reddy and al in 2010 [24].

Moreover, the high value of the correlation coefficient of the intra-particle diffusion model for NS $\left(R^{2}=0.9138\right)$ shows that the adsorption process is also con- 
trolled by diffusion. But this diffusion is not the limiting step in the absorption mechanism as shown by Belaid et al. in 2010 in their work [25].

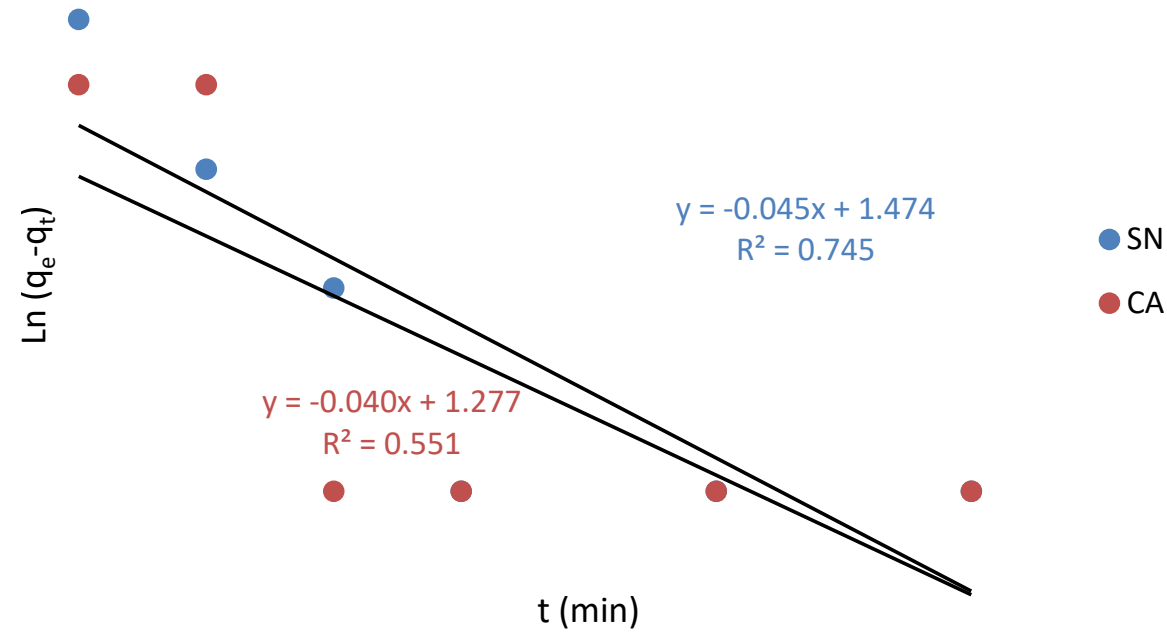

Figure 9. Linear transform of the pseudo-first order kinetic model.

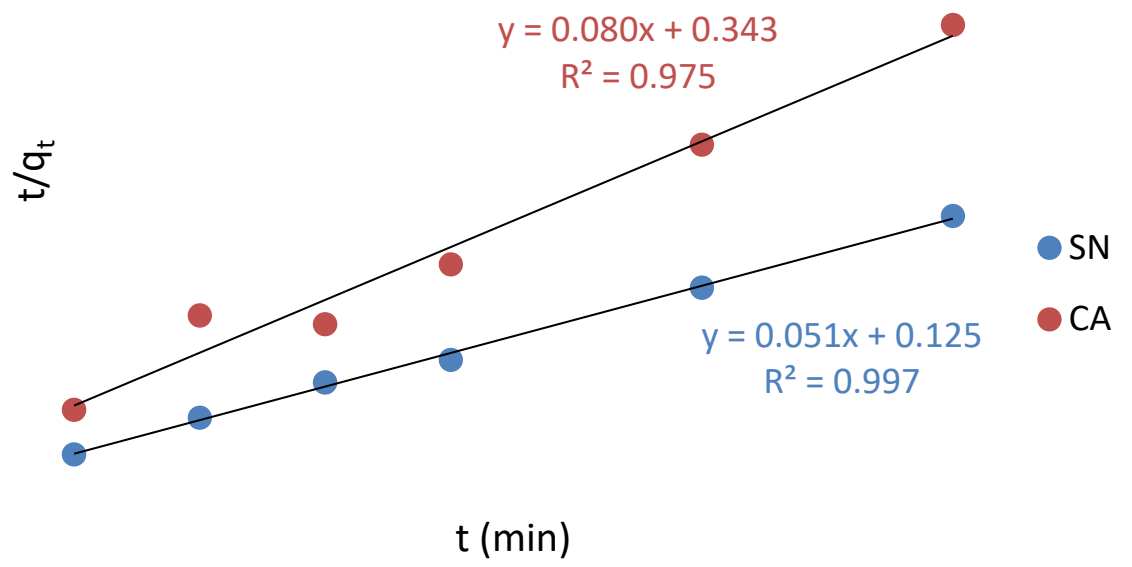

Figure 10. Linear transformation of the pseudo-second order kinetic model.

Table 4. Speed constants and correlation coefficients of kinetic models.

\begin{tabular}{cccc}
\hline kinetic models & Parameters & NS & AC \\
\hline \multirow{2}{*}{ Pseudo-first order } & $R^{2}$ & 0.7458 & 0.5515 \\
& $K_{1}\left(\mathrm{~min}^{-1}\right)$ & 0.0454 & 0.0408 \\
\hline \multirow{3}{*}{ Pseudo-second order } & $R^{2}$ & $\mathbf{0 . 9 9 7 9}$ & $\mathbf{0 . 9 7 5 2}$ \\
& $q_{m}(\mathrm{mg} / \mathrm{g})$ & 19.61 & 12.47 \\
& $q_{e}(\mathrm{mg} / \mathrm{g})$ & 18.3 & 11 \\
& $K_{2} \cdot 10^{-2}(\mathrm{~g} / \mathrm{mg} / \mathrm{min})$ & 2.08 & 1.87 \\
\hline \multirow{2}{*}{ Elovich } & $R^{2}$ & 0.9145 & $\mathbf{0 . 7 1 9 2}$ \\
& $\alpha(\mathrm{mg} / \mathrm{g} / \mathrm{min})$ & 94.2293 & 9.2997 \\
& $\beta(\mathrm{g} / \mathrm{mg})$ & 0.3830 & 0.4319 \\
\hline Intra-particulate diffusion & $R^{2}$ & $\mathbf{0 . 8 3 6 4}$ & $\mathbf{0 . 6 4 8 2}$ \\
& $C_{i}$ & 11.269 & 4.9444 \\
& $K_{i d}$ & 1.26 & 1.1092 \\
\hline
\end{tabular}




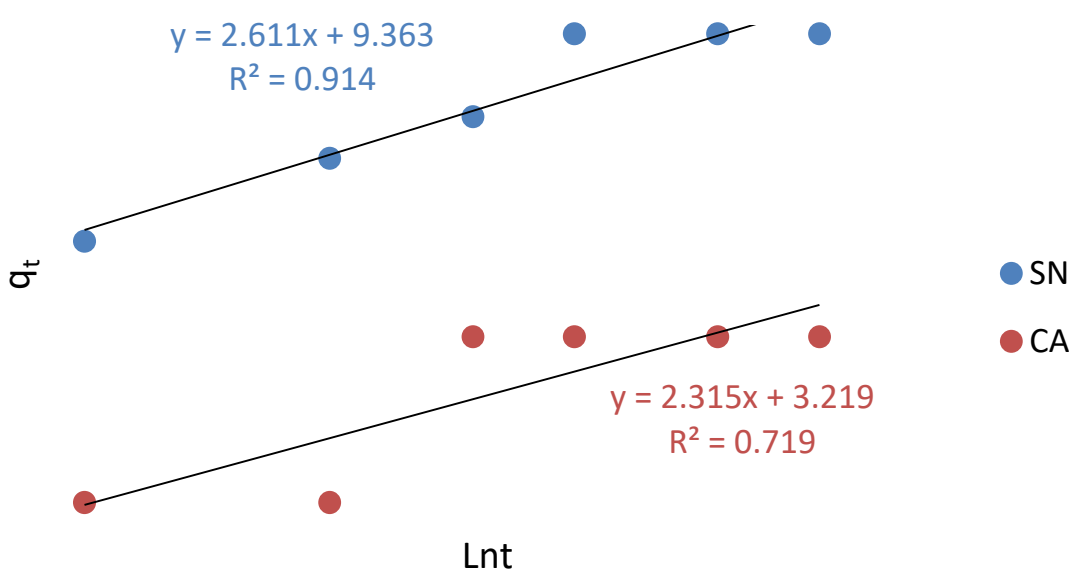

Figure 11. Linear transform of the Elovich model.

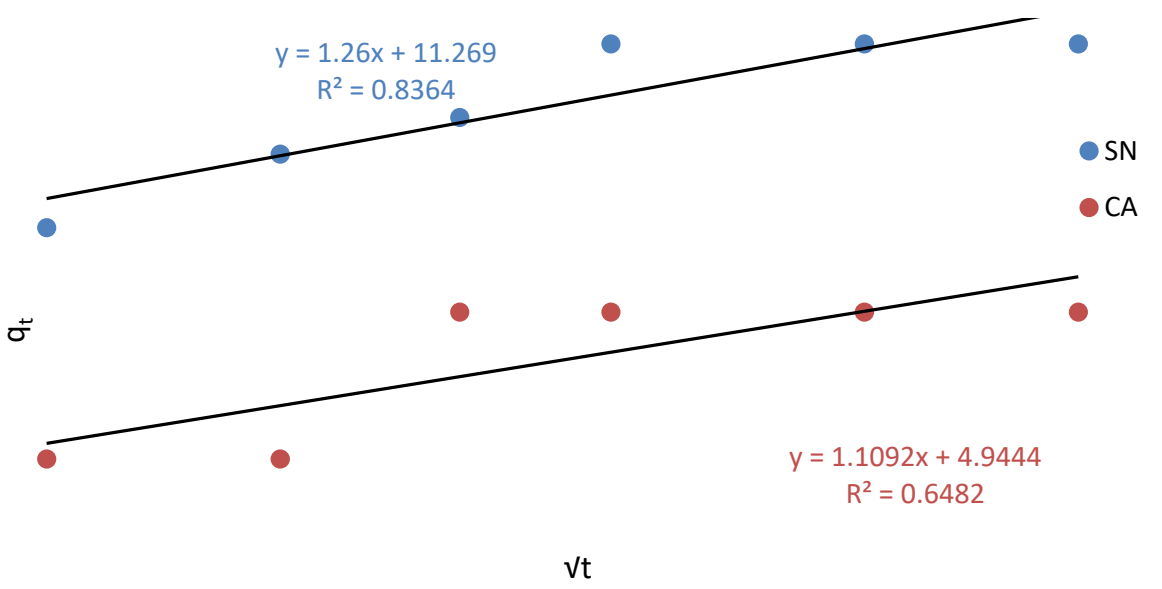

Figure 12. Linear transform of the intra-particle diffusion model.

\section{Conclusion}

This work focused on the adsorption of copper (II) ions in an aqueous solution by a natural smectite and an activated carbon prepared from the shells of kola nuts. From the study of the adsorption parameters, it emerges that the quantity of copper (II) ions adsorbed increases with the stirring time until reaching equilibrium after $20 \mathrm{~min}$ for the NS and $15 \mathrm{~min}$ for the AC. This quantity decreases with the increase in the mass of the adsorbents, the optimum mass being $0.05 \mathrm{~g}$ of the adsorbents. The $\mathrm{pH}$ corresponding to the maximum adsorption is 3.5 for adsorbents. It also increases with the initial concentration of copper (II) ions and is maximum at $1800 \mathrm{mg} / \mathrm{L}$.

The equilibrium study showed that the Langmuir, Freundlich and Tempkin models well describe the adsorption of copper (II) ions by AC, while only the Langmuir model describes the adsorption of copper (II) ions well by NS.

The kinetic study showed that the pseudo-second order kinetic model best describes the adsorption of copper (II) ions by adsorbents and that chemisorption is the limiting step in this process. NS and AC are efficient at adsorbing copper (II) ions in aqueous solution, but AC adsorbs copper (II) ions better than NS. 


\section{Conflicts of Interest}

The authors declare no conflicts of interest regarding the publication of this paper.

\section{References}

[1] Sedira, N. (2013) Etude de l'adsorption des métaux lourds sur un charbon actif issu de noyaux de dattes. Thèse de Doctorat, Université Mohamed Chérif Messaadia Souk-Ahras, 1-36.

[2] Schorff, P.S. and Perrin, R. (1997) Chimie Industrielle. 2ed Edition, Masson.

[3] World Health Organization (2011) Guidelines for Drinking-Water Quality. 3rd Edition, Geneva.

[4] Omur-Ozbek, D.P. (2011) Retronasal Perception and Flavour Thresholds of Iron and Copper in Drinking Water. Journal Water Health, 9, 1-9. https://doi.org/10.2166/wh.2011.157b

[5] Athéba, G.P., N’guadi, B.A., Dongui, B.K., Kra, D.O., Gbassi, K.G. and Trokourey, A. (2015) Adsorption du Butyllparabène sur du Charbon Activé à base des Coques de Coco Provenant de Cote d'Ivoire. International Journal of Innovation and Scientific Research, 13, 530-541.

[6] Ketcha, M.J., Ngomo, M.H., Tcheka, T.C., Abdoul, R.N., Djoyo, S.H. and Kouatou, D. (2009) Batch Equilibrium Adsorption of Cyanides from Aqueous Solution onto Copper and Nickel Impregnated Powder AC and Clay. Journal of Environmental Protection Science, 3, 53-57.

[7] Zue, M.M., Mekui, M.M.C., Eba, F. and Ondo, A.J. (2020) Study of the Adsorption Equilibrium of Methylene Blue from Aqueous Solution onto Activated Carbon of Coulaedulis Nut Shells. Research Journal of Chemistry and Environment, 24, 40-50.

[8] Zue, M.M., Makani, T. and Eba, F. (2016) Removal of Mn (II) from Aqueous Solution by Activated Carbons Prepared from Coula edulis Nut Shell. Journal of Environmental Science and Technology, 9, 226-237. https://doi.org/10.3923/jest.2016.226.237

[9] Bouchelkia, N. (2015) Etude de l'élimination du plomb, du zinc et du cadmium par adsorption, sur un charbonactifpreparé à base des noyaux de jujube. Mémoire, Université de Béjaia.

[10] Mellah, A., Harik, D. and Haouchine, O. (2014) Study of the Effect of Concentration on the Adsorption of Two Drugs (Phenobarbital and Ibuprofen) on Powdered Activated Carbon F400. Journal of Materials and Environmental Science, 5, 2413-2417.

[11] Almardni, F. (2008) Etude de l'adsorption du pesticide Bromacilsurcharbonactif en poudre en milieu aqueux. Effetcompétiteur des matièresorganiquesnaturelles, Thèse, Université de Poitiers.

[12] Ndongo, K.G., Ndi, N.J., Belibi, B.D.P., Kouotou, D., Tagne, M.G., Dina, J.D.D. and Ketcha, M.J. (2015) Adsorption of Zinc (II) Ions from Aqueous Solution onto Kaolinite and Metakaolinite. Der Pharma Chemica, 7, 51-58.

[13] Ghogomu, J.N., Noufame, T.D., Tamungang, N.B.E., Ajifack, L.D., Ndi, N.J. and Ketcha, M.J. (2014) Adsorption of Phenol from Aqueous Solutions onto Natural and Thermally Modified Kaolinitic Materials. International Journal Biology Chemical Sciences, 8, 2325-2338. https://doi.org/10.4314/ijbcs.v8i5.35

[14] Ndi, N.J., Ketcha, M.J., Anagho, G.S., Ghogomu, N.J. and Belibi, B.D.P. (2014) Physical and Chemical Characteristics of Activated Carbon Prepared by Pyrolysis of Chemically Treated Cola Nut (Cola Acuminata) Shells Wastes and Its Ability to Adsorb Or- 
ganics. International Journal of Advanced Chemical Technology, 3, 1-13.

[15] Belibi, B.D.P., Rivallin, M., Cerneaux, S., Ngassoum, M. and Cretin, M. (2014) Elaboration of Low-Cost Ceramic Membrane Based on Local Material for Microfiltration of Particle from Drinking Water. Journal of Applicable Chemistry, 3, 1991-2003.

[16] Ouakouak, A.K. and Youcef, L. (2016) Adsorption des ions $\mathrm{Cu}^{2+}$ sur un charbon actif en poudre et une bentonite sodique. Larhyss Journal, 27, 39-61.

[17] Ajifack, D.L., Ghogomu, J.N., Noufame, T.D., Ndi, N.J. and Ketcha, J.M. (2014) Adsorption of $\mathrm{Cu}$ (II) Ions from Aqueous Solution onto Chemically Prepared Activated Carbon from Theobroma Cacao. British Journal of Applied Science \& Technology, 4, 5021-5044. https://doi.org/10.9734/BJAST/2014/12742

[18] Zing, Z.B., Belibi, B.D.P., Ankoro, N.O., Kouotou, D. and Ndi, N.J. (2016) Batch Adsorption of Ammonium Ions from Synthetic Wastewater Using Local Cameroonian Clay and $\mathrm{ZnCl}_{2}$ Activated Carbon. International Journal of Engineering and Applied Sciences, 3, 75-85.

[19] Siéwé, J.M., Woumfo, E.D., Djomgoue, P. and Njopwouo, D. (2015) Activation of Clay Surface Sites of Bambouto's Andosol (Cameroon) with Phosphate Ions: Application for Copper Fixation in Aqueous Solution. Applied Clay Science, 114, 31-39. https://doi.org/10.1016/j.clay.2015.05.003

[20] Ghaedi, A.M., Vafaei, A., Iravani, N., Keshavarz, M., Rad, M., Tyagi, I., Agarwal, S. and Gupta, V.K. (2015) Adsorption of Copper (II) Using Modified Carbon Prepared from Pomegranate Wood: Optimization by Bee Algorithm and Response Surface Methodology. Journal of Molecular Liquids, 206, 195-206.

https://doi.org/10.1016/j.molliq.2015.02.029

[21] Essomba, J.S., Ndi, N.J., Belibi, B.D.P., Tagne, G.M. and Ketcha, J.M. (2014) Adsorption of Cadmium (II) Ions from Aqueous Solution onto Kaolinite and Metakaolinite. Pure and Applied Chemical Sciences, 2, 11-30. https://doi.org/10.12988/pacs.2014.31017

[22] Ivanova, E., Karsheva, M. and Koumanova, B. (2010) Adsorption of Ammonium Ions onto Natural Zeolite. Journal of the University of Chemical Technology and Metallurgy, 45, 295-303.

[23] Ketcha, M.J., Dongmo, S. and Dinka'a, D.N. (2012) Kinetic and Thermodynamic Studies of the Adsorption of Nickel (II) Ions from Aqueous Solutions by Smectite Clay from SABGA-CAMEROON. International Journal of Current Research, 4, 162-167.

[24] Reddy, D.H.K., Harinath, Y., Seshaiah, K. and Reddy, A.V.R. (2010) Biosorption of $\mathrm{Pb}$ (II) from Aqueous Solution Using Chemically Modified Moringa oleifera Tree Leaves. Chemical Engineering Journal, 162, 626-634. https://doi.org/10.1016/j.cej.2010.06.010

[25] Belaid, K.D. and Kacha, S. (2010) Etude cinétique et thermodynamique de l'adsorption des colorants basiques. Revue des Sciences de P eau, 24, 131-144. https://doi.org/10.7202/1006107ar 